\title{
Samlet litteraturliste
}

Becker Jensen, Leif (1995): Under henvisning til den fremsendte skrivelse... I:

Pedersen, Karl Peder; Ilsøe, Grethe; Tamm, Ditlev (red.): På given foranledning. En antologi om dansk forvaltningskultur. Jurist- og Økonomforbundets Forlag

Becker Jensen, Leif (1998): Kancellistil eller Anders And-sprog. 2. udgave, Roskilde Universitetsforlag

Becker Jensen, Leif (2000): Ud af elfenbenstårnet. 2. udg. 3. oplag. Roskilde Universitetsforlag

Becker Jensen, Leif (2003): Den sproglige dåseåbner. Om at formidle faglig viden forståeligt. 1. udg. 2. oplag. Roskilde Universitetsforlag

Becker Jensen, Leif (2007): På patientens promisser - en brugsbog om skriftlig patientinformation. 2. udgave, Roskilde Universitetsforlag

Bing, J. (1986): Om tolkning av enkeltord - særlig i lovtekst. I: Dahl, T.; Holt, A.;

Skard, H. (red.): Rettferdighed og styring: En studenthilsen til Torstein Eckhoff. Universitetsforlaget, Oslo

Blume, P. (1985): Dommens sprog. I: Ugeskrift for Retsvoesen, afd. B. s. 313-20.

Bruun, Henrik; Malmsten, Ann-Marie; Palmgren, Sten (red.) (2004): Svenskt lagspråk i Finland. Statsrådets svenska språknemnd och Schildts Förlag, Helsingfors

Dahlsgaard, Anna; Nielsen, Jørgen Christian (red.) (1998): Sprogstrategi og Sprogpolitik - inspiration, ideer og erfaring. Erhvervssprogligt Forbund, København 
Dybdal, Ida (1985): Ministeriet og borgeren. I: Sproglige kløfter. C.A. Reitzel, København

Ehrenberg-Sundin, Barbro; Lundin, Kerstin; Westman, Margareta; Wedin, Åsa (2003): Att skriva bättre i jobbet. En basbok om brukstexter. Norstedts Juridik, Stockholm

Elektronisk kommunikation til gavn for kvaliteten. (2004) MedCom, Odense

Eriksen, Jens-Martin (1984): Svore ord - og lette. 4. udg. Statens Information, eksp. Gyldendal, 1997. København

Eyben, W.E. von (1989): Dommen - Sproget. I: Juridisk Grundbog, bd. 3. s. 11-62. 4. udg. Jurist- og Økonomforbundets Forlag, København

Fretland, Jan Olav; Hovdenak, Marit (red.) (2005): Forståeleg språk for alle. Rapport frå ein nordisk konference om klarspråk, Kongsberg, 4.-6. november 2004. Språkrådet, Oslo

Fretland, Jan Olav m.fl. (1985): På godt norsk. Oslo

Gammeltoft-Hansen, Hans (1995): Ombudsmandens skriftsprog. I: Folketingets Ombudsmands beretning. S. 661 ff. København

Grønning, Anette (2001): Sprogstrategi som en del af en organisationskultur. Syddansk Universitet, (specialeafhandling)

Gundersen, Dag (1989): Rettsspråket - tradisjon, påvirkning, forståelighet og egenart. I: Vinje, Finn-Erik: Språket i lover og annet regelverk. Oslo

Hackos, JoAnn (1994): Managing Your Documentation Projects. John Wiley \& Sons, Inc.

Hamburger, Arne (1986): Godt nyt om juristdansk. I: Nyt fra Sprognœevnet. nr. 2. Dansk Sprognævn, København

Hamburger, Arne, (1988): Officiel sprogbrug. I: Sproget her og nu. Dansk Sprognævns Skrifter (14), København

Hansen, Erik (1987): Ping- og pampersprog. 2. udg, (1. udg. 1971). København

Hansen, Peter Gorm (2005): Skærpede krav til kommunikation og sproglige kompetencer. I: International Fagkommunikation - globalisering og lokalisering. Dansk Selskab for Fagsprog og Fagkommunikation, Frederiksberg Harms Larsen, Peter (1987): Ned med fagsproget! - om fagsprog som kommunikationsmodstand. I: ARK 39. s. F1-F30. København

Harms Larsen, Peter (1997): Skriv sundere. En kritisk brugsbog for sygeplejersker om skriftlig kommunikation. Teknisk Forlag, København 
Hauge, Rikke E.; Stokkeland, Jostein (red.) (2005): Språkkvaliteten i film-og fjernsynsteksting. Rapport frå ein konference i Oslo, mars 2005. Språkrådet, Oslo

Hällstrøm, Charlotta af (red.) (2003): Klarspråk. Rapport från en konferens den 20.-22. oktober 2000 på Hanaholmen i Esbo, Finland. Nordiska språkrådet, Helsingfors

Information til tiden. Betoenkning fra Udvalget om Offentlig Informationspolitik - Betoenkning $n r$. 1342. (1997). Forskningsministeriet. Findes på videnskabsministeriet.dk.

Jarvad, Pia (2001): De flossede rande. Det juridiske sprog og almensproget på kollisionskurs. I: E som Erik H som Hansen. Sproglige åbninger. Festskrift til Erik Hansen 18. september 2001. s. 289-302. Hans Reitzels Forlag, København

Kankaanpää, Salli (2006): Hallinnon lehdistötiedotteiden kieli. [Språket i förvaltningens pressmeddelanden. English abstract: Language of administrative press releases.] Suomalaisen Kirjallisuuden Seura, Helsingfors

Karker, A. (1973): Dansk lovsprog og kancellistil. I: Sprog i Norden. s. 61-73. Gyldendal, København

Karker, A. (1982): Ti år efter eller Lovsprogets forandring. I: Festskrift til professor, dr. jur. W.E. von Eyben. s. 191-207. Juristforbundet, København

Karker, A. (1993): Dansk i EF - en situationsrapport om sproget. G.E.C. Gads Forlag, København

Kiselman, Christer (2001): Svenskt fackspråk inom teknik, matematik och naturvetenskap. I: Libens merito. Festskrift till Stig Strömholm.. s. 225-243. Acta Academiae Regiae Scientiarum Upsaliensis, Uppsala

Klarspråk lönar sig - klarspråksarbete i kommuner, landsting och statliga myndigheter. DS 2006:10. Fritzes, Stockholm.

Klarspråksbulletinen. - trycks i 4000 exemplar i kvartalet och distribueras till cirka 3500 prenumeranter på bland annat statliga myndigheter, kommuner, landsting. Det är gratis att prenumerera på den. Den kan också laddas ner på www. sprakradet.se

Lathund för webbskribenter. (2004). - kan beställas gratis från expedition@sprakradet.se

Lindgren, Birgitta (red.) (1999): Nordiskt klarspråksseminaium. Rapport från ett seminarium den 14-16 maj 1998 i Stockholm. Nordiska Språkrådet, Stockholm 
Lundin, Kerstin; Åsa Wedin (2000): Fästa prat på pränt. Hur man skriver läsvärda protokoll och minnesanteckningar. Norstedts Juridik, Stockholm

Lundin, Kerstin (1990): Texter som når fram. En handbok för skribenter $i$ Stockholms stad. Stockholms stads utbildningscentrum

Lundin, Kerstin; Åsa Wedin (2007): Klarspråk i socialtjänsten. Hur man skriver lättlästa beslut, utredningar och journaler. Gothia förlag, Stockholm

Løj, Mogens; Wille, Niels Erik (1985): Kan vi undvære passiv? Eller: Kan passiv virkelig undværes? I: Nydanske studier og almen kommunikationsteori. nr. 15. s. 5-42. Akademisk, København

Madsen, Bodil Nistrup (1999): Terminologi. Bind 1: Principper og metoder, Bind 2: $\emptyset$ velser og eksempler. Gads Forlag, København

Madsen, Bodil Nistrup (2003): Den afgørende forskel: Hvorfor det ene ord ikke er lige så godt som det andet. I: Ind med sproget! En artikelsamling om sprog i og for erhvervslivet. s. 67-77. Lingtech A/S, København

Madsen, Bodil Nistrup (2005): Håndbog i begrebsarbejde. Del 1: Principper, Del 2: Metoder og arbejdsforløb. Sundhedsstyrelsen, København (publiceret på http:// begrebsbasen.sst)

Madsen, Bodil Nistrup (2006): Terminologi og standardisering - metoder og værktøjer. I: Sprogteknologi i dansk perspektiv. En samling artikler om sprogforskning og automatisk sprogbehandling. Red. af: Braasch, Anna mfl. s. 99-121. C.A. Reitzels forlag, København

Madsen, Bodil Nistrup; Thomsen, Hanne Erdman (2006): Terminological ontologies in normative terminology work. I: TSTT 2006 - International Conference on Terminology, Standardization and Technology Transfer. Red. af Wang mfl. s. 122134. Encyclopedia of China Publishing House, Beijing

Møller, B. (1983): Møde med skrankesproget og testamente til en flink fyr. Dafolo, København

Møller, B.; Hansen, E. (1981): - og uden omsvøb, tak. Statens Informationstjeneste, København

Møller, B.; Jens Olsen (2001): Juridisk Formidling. At skrive juridiske tekster. Nyt Juridisk Forlag, København

Mårdsjö, Karin (1987): Informér bedre om teknik. Teknisk Forlag

NBS 07 (2005): Terminologi. Forebyggelse, sundhedsfremme og folkesundhed. København 
Nøstebø (2003): Mot en modell for tekstoptimering. Universitetet i Oslo

Platzack, Christer (1974): Språket och läsbarheten. W.W.K. Gleerup, Lund

Rosenheimer, Lene (2005): Få budskabet ud. Om formidling af juridiske tekster. Jurist- og Økonomforbundets Forlag.

Spang-Hanssen, Henning (1983): Fagsprog og almensprog. I: SAML 10. s. 85-100.

Institut for Anvendt og Matematisk Lingvistik. Københavns Universitet

Spleth, P. (1985): Domssproget - et svensk reformforslag og en dansk kritik. I: Ugeskrift for Retsvoesen, afd. B. s. 345-51.

SprogMagisteren. Konsulentfirmaet Bøje Larsen, Korsgårdsvej 28, DK-2920 Charlottenlund (pc-program).

Stray Jørgensen, Peter (2000): Klart sprog - i opgaver på videregående uddannelser. 2. udg. Samfundslitteratur, København

Suonuuti, Seija (2005): Towards Better Communication in a Global Company. I: International Fagkommunikation - globalisering og lokalisering. Dansk Selskab for Fagsprog og Fagkommunikation, Frederiksberg

Söderberg, Anne-Marie (2005): Globalisering og lokalisering i en virksomhedskontekst. I: International Fagkommunikation - globalisering og lokalisering. Dansk Selskab for Fagsprog og Fagkommunikation, Frederiksberg

Sørensen, Puk Lundgaard (2006): Language Strategy in a merger Process. I: Language at Work. nr. 1.

Texter för medborgarna - hur vet man om de är bra? - konferensrapport. (2006). - kan beställas gratis från expedition@sprakradet.se

Veirup, Hans (1995): Klart og enkelt - kort og godt. Sproglige råd til den fagmand, der skriver til gud og hvermand. Forlaget systime.

Vinje, Finn-Erik (1977): Norsk i embets medfør. Damm, Oslo

Vinje, Finn-Erik (1990): Lovlig språk. Om språk og stil i lover og annet regelverk - en veiledning. Justisdepartementet, Oslo

Visst går det att förändra myndighetsspråket. En rapport från Språkvårdsprojektet (1993). Allmänna förlaget, Stockholm

Waaben, Knud (1995): Følelse og vurdering i juridisk sprog. I: Mål \& Mole. 1995/3. 18. årg. s. 21-26 